\title{
A REPRESENTAÇÃO DA IMAGEM PÚBLICA NAS ENTREVISTAS
}

\author{
Leonor Lopes Fávero*
}

O objetivo deste trabalho é estudar a representação da imagem pública na linguagem da mídia, especificamente nas entrevistas apresentadas pela televisão na cidade de São Paulo. Consideraremos o conceito de face utilizado por Brown e Levinson (1987) para discutir que as estratégias de polidez empregadas durante a interação derivam da necessidade de salvaguardar a face.

Partiremos do princípio de que há vários tipos de ações que criam conflitos de interesse e tais ações podem pôr em perigo a imagem pública do locutor ou de seu interlocutor; em casos como esse, a polidez é necessária para amenizar a ameaça potencial à face do interlocutor. $\mathrm{O}$ estudo das estratégias de polidez implica a abordagem de alguns fatores imprescindíveis, tais como: relações de poder, distância social, grau de imposição do próprio ato e a conjunção desses fatores determina a seleção das estratégias durante a atividade discursiva.

Devido ao corpus selecionado, o centro de interesse, neste trabalho, estará voltado, por um lado, para as entrevistas em que ocorre certa polemização, já que se instaura o debate de idéias, o confronto de opiniões (programa Entrevista Coletiva, apresentado na TV Bandeirantes); por outro, para entrevistas onde se traça um perfil humano (Programa Jô Onze e Meia, apresentado no SBT, e Juca Kfouri, veiculado pela CNT). Nessas entrevistas, há um documentador e um informante que estão fisicamente presentes, um diante do outro, portanto numa situação comunicativa direta, 
FÁVERO, Leonor Lopes. A representação da imagem pública nas entrevistas.

de interação face a face. Entretanto, há certo distanciamento entre os interlocutores, embora - em geral - o documentador procure minimizar essas condições durante $o$ evento. Já no segundo tipo, existem dois tipos de situação:

a - programa Entrevista Coletiva: um mediador (jornalista Francisco Pinheiro) e quatro entrevistadores (jornalistas especializados) que fazem as perguntas ao entrevistado;

b - programa Jô Onze e Meia: um entrevistador (Jô Soares) e um entrevistado, em geral pessoa de destaque na sociedade: artista, jornalista, modelo, diplomata, cartunista; programa Juca Kfouri: um entrevistador (Juca Kfouri) e um entrevistado, em geral pessoa que tem sido notícia no momento: jornalista, político, locutor esportivo, entre outros.

Quanto às entrevistas do Projeto NURC, o objetivo é deixar o interlocutor falar, não importando o que possa dizer, mas o modo como o diz. Considerando-se a proposta do Projeto, não há preocupação com o conteúdo, mas com o lingüístico, colocando ao documentador a determinação e o direcionamento do assunto, resultando num grau menor de dialogicidade. Esses dados auxiliam a pensar a interlocução, levando-se em conta os diferentes tipos de configuração contextual (entrevista em Ciências Humanas e entrevista jornalística) em que ocorre o evento e as consequiências para os distintos processos interacionais.

Partiremos do princípio de que há vários tipos de ações que criam conflitos de interesse e tais conflitos podem pôr em perigo a imagem pública do locutor ou de seu interlocutor; em casos como esse, a polidez é necessária para amenizar a ameaça potencial à face dos interlocutores. O estudo das estratégias de polidez implica a abordagem de alguns fatores imprescindíveis, tais como: relações de poder, distância social, variação lingüística, grau de imposição do próprio ato e a conjunção desses fatores determina a seleção das estratégias durante a atividade discursiva.

Em suas várias aplicações, a entrevista é uma técnica de interação social. Por meio dela, busca-se uma interpenetração informativa que visa a quebrar isolamentos sociais, grupais, individuais; pode ainda servir à pluralização de vozes e à distribuição democrática da informação. Em seus diversos usos nas Ciências Humanas, constitui sempre um meio cujo objetivo fundamental é o inter-relacionamento humano. 
Enquanto gênero jornålístico, a entrevista pode ser definida como uma técnica eficiente na obtenção de respostas pré-pautadas por um questionário. Entretanto, não será uma comunicação humana em que a verdadeira interação se deixará notar, dado que as relações entre os participantes - entrevistador e entrevistado - não atingem o diálogo em sua plenitude.

Se na conversação espontânea, a comunicação entre os interlocutores deixa transparecer um tom mais "intimista”, na entrevista - conforme já apontou Barros (1991: 254) - "rompe-se o dialogismo estreito (eu e você, aqui e agora) e alarga-se a circulação do dizer na sociedade". Três diálogos são instaurados durante a atividade:

- entrevistador e entrevistado;

- entrevistado e audiência (público: leitor, ouvinte, telespectador);

- entrevistador e audiência.

Cria-se um jogo duplo de comunicação e interação entre entrevistador e entrevistado, visto que há sempre a possibilidade de inversão e reciprocidade da relação eu$t u$ : o entrevistado pode, a qualquer momento, tomar o turno e mudar o tópico discursivo em desenvolvimento, alterando, assim, a direção da entrevista. Entretanto, as relações estabelecidas entre entrevistador/entrevistado e a audiência não são passíveis de inversão: o público é construído a partir de traços genéricos, sendo uma espécie de extensão dos papéis do ouvinte, na conversação natural. Tais traços permitem elaborar um horizonte de expectativas que condicionam o evento.

Entrevistador e entrevistado têm a tarefa de informar e convencer o público. Desempenham, portanto, um duplo papel na interação: são cúmplices, no que diz respeito à comunicação, e oponentes, quanto à conquista desse mesmo público.

Dessa forma, as entrevistas ora tendem para o pólo do contrato ora para o da polêmica. No primeiro caso, os interlocutores buscam causar boa impressão na audiência, para isso tentam respeitar a fala do outro, costumam ceder o turno, evitam traços que demonstrem agressividade. Já no estilo polêmico, a interação pode apresentar inclusive a desqualificação de um dos interlocutores. Em quaisquer tipos de entrevista, contratual ou polêmica, entrevistador e entrevistado buscam somente interagir com o destinatário desse jogo interacional, que é a audiência, por isso os laços que os envolve são considerados frouxos, sejam eles cúmplices ou oponentes.

Em relação aos demais textos conversacionais, a entrevista se distingue por três aspectos: o número de participantes envolvidos em sua organização; o caráter assimétrico da interação; o planejamento e o tempo de elaboração. Vejamos, a seguir, cada um desses pontos. 
Com o intuito de observar o processo interacional nas entrevistas, é preciso considerar a situação, as características dos participantes e as estratégias por eles utilizadas durante o evento. Importa observar algumas características desse tipo de interação, bem como as condições de poder evidenciadas por certas marcas. Em outras palavras, é necessário atentar para um conjunto de traços que evidenciam o esquema de dominância esboçado no transcorrer do diálogo.

Embora em muitas entrevistas haja - a princípio - certa condição de igualdade (não existe qualquer hierarquia pré-estabelecida entre os participantes), a interação não se fixa apenas em cumplicidade e solidariedade, mas também em certa disputa, na medida em que os interlocutores fazem parte de um jogo de linguagem que se instaura através de um processo de negociações, trocas, normas partilhadas, concessões.

Durante as entrevistas, os participantes não apenas expressam suas idéias e opiniões, trocam informações, mas também - ao cumprir seus papéis - constroem juntos o texto, buscando atuar sobre o outro e sobre a audiência. Conforme aponta Kerbrat-Orecchioni (1990: 89), "todos os destinatários de uma mensagem, mesmo aqueles que o são indiretamente, desempenham um papel importante no desenvolvimento da interação".

Para diferenciar os vários níveis de organização, é necessário considerar, de acordo com as sugestões de Charaudeau (1984), as particularidades do modo de presença dos participantes do evento interacional e o modo de relação que os interdefine em função da configuração contextual.

Isso equivale a dizer que essa situação única não é estabelecida previamente, mas é algo que se constrói a partir da negociação entre os interlocutores e que depende diretamente das competências e intenções de cada um deles, bem como do modo como essa atividade se instaura e se desenvolve no intercurso conversacional.

As entrevistas pertencentes ao material do Projeto NURC/SP permitem um bom trabalho relativo às especificidades do texto oral; entretanto, não contêm, em suas transcrições, os aspectos referentes aos gestos, visto que as gravações foram feitas apenas em áudio. Assim, a dimensão abrangida pelo olhar, a interferência que esse aspecto poderia executar no texto lingüístico e as supostas conseqüências para a situação interacional somente serão trabalhadas no material relativo às entrevistas de televisão, cuja transcrição menciona alguns aspectos referentes aos gestos e ao olhar, significativos para a atividade conversacional.

A entrevista define-se por apresentar uma interação assimétrica, dado que os papéis dos interlocutores (entrevistador e entrevistado) são distintos. Ao entrevistador 
cabe escolher o tópico discursivo e a direção da conversação: quando ou como interromper ou terminar (isto fica bem claro na entrevista jornalística), a distribuição dos turnos, o caráter contratual ou polêmico, entre outros. Por sua vez, o entrevistado pode conservar o turno por mais tempo, pois é a ele que se quer ouvir.

No entanto, o conceito de assimetria interacional está relacionado não só às funções dos interlocutores na situação comunicativa, mas principalmente a seus papéis sociais e a suas características individuais. Há casos em que a importância social do entrevistado leva à inversão do equilíbrio da entrevista: o entrevistado seleciona os tópicos e decide quando passar o turno. Por sua vez, há entrevistadores peculiares que dominam a entrevista e não deixam ao entrevistado nem mesmo os turnos que lhe são devidos.

Na entrevista, distinguem-se três momentos: o de preparação da pauta, o da entrevista propriamente dita e o da edição. Quando se fala em planejamento da conversação, é importante salientar que esse planejamento existe pelo menos da parte do entrevistador, mas também pode ocorrer, em certos casos, da parte do entrevistado. Desse modo, os participantes têm mais tempo de elaboração, o que torna possível uma diminuição das marcas de reformulação textual. Nesse sentido, a entrevista deve ser vista como um caso particular de produção oral.

Por sua vez, a edição da entrevista traz à tona um outro interlocutor que também participa da produção final do texto e cuja marca se faz notar juntamente com as dos demais participantes (entrevistador, entrevistado, audiência). Cabe apontar que, nas entrevistas em que se conservam os traços da oralidade, podem ocorrer alterações nos efeitos de sentido produzidos. Vale ainda mencionar as entrevistas feitas ao vivo, em que a falta de uma edição final permite que a espontaneidade aflore em detrimento do planejamento conversacional.

Para atingir os objetivos conversacionais, o locutor precisa atuar de algum modo sobre o seu intelocutor. Nesse sentido, é fundamental que a atividade interacional esteja voltada para fatores sociais, como: idade, sexo, grau de conhecimento prévio, posição social, consideradas enquanto variáveis que determinam o grau de distanciamento entre os participantes da conversação. Conhecer as regras sociais implica saber agir de acordo com os padrões que regem a preservação da imagem e distinguir quando ela está sendo utilizada ou não.

Podemos afirmar que a comunicação verbal é uma atividade intencional dirigida para a obtenção de determinado objetivo e o uso adequado da linguagem pode constituir um elemento determinante para o êxito do objetivo pretendido. O locutor deve, 
assim, levar em conta que seu enunciado esteja de acordo com su ı intenções e, principalmente, com a categoria e o papel de seu interlocutor. Portanto, o uso conveniente de todos os meios de que a linguagem dispõe é fator primordial para a manutenção de uma interação cordial, especialmente quando o falante deve enfrentar um conflito entre seus objetivos e os de seu interlocutor e quer, muitas vezes, não romper suas boas relações. Neste sentido, a polidez pode ser entendida como um conjunto de estratégias discursivas destinadas a evitar ou amenizar o conflito.

\section{Bibliografia}

BARROS, D. L. P. de (1991) Entrevista: texto e conversação. In: Anais do XXXIX Seminário do GEL. Franca: UNIFRAN, p. 254-261.

BROWN, P. e LEVINSON, S. (1987) Politeness. Some Universals in Language Use. Cambridge: Cambridge University Press.

CHARAUDEAU, P. (1995) Une analyse sémiolinquistique du discours. Langages, 117, 3. Paris: Larousse.

KERBRAT-ORECCHIONI, C. (1984) Les négociations conversationnelles. Verbum. Tomo VII. Nancy: Presses Universitaires de Nancy.

LEECH, G. (1983) Principles of Pragmatics. London: Longman. 